\title{
Growth Hormone-Releasing Effects of Whole Body Vibration Alone or Combined with Squatting plus External Load in Severely Obese Female Subjects
}

\author{
Marialuisa Giunta ${ }^{a, b} \quad$ Marco Cardinale $e^{c, d, e} \quad$ Fiorenza Agosti ${ }^{a}$ \\ Alessandra Patrizi ${ }^{a}$ Emanuele Compria Antonello E. Rigamonti ${ }^{\text {b }}$ \\ Alessandro Sartorio ${ }^{a}, f$
}

a Istituto Auxologico Italiano, Laboratorio Sperimentale di Ricerche Auxo-endocrinologiche, IRCCS, b Dipartimento di Farmacologia Medica, Università degli Studi di Milano, Milan, Italy,

${ }^{\mathrm{C} B r i t i s h}$ Olympic Association, ${ }^{\mathrm{d}}$ Institute of Sport, Exercise and Health, University College London, London, e School of Medical Sciences, University of Aberdeen, Aberdeen, UK, ${ }^{f}$ Istituto Auxologico Italiano, Divisione Malattie Metaboliche, IRCCS, Piancavallo, Italy

\section{Key Words}

Growth hormone $\cdot$ Obesity $\cdot$ Whole body vibration $\cdot$ Lactate $\cdot$ Squatting

\begin{abstract}
Background: Whole body vibration (WBV) has been reported to exert growth hormone(GH)releasing effects in healthy subjects. Despite the potential of WBV to positively affect body composition changes via lipolytic effects, few studies have been performed in obese subjects to date. Methods: This study evaluated the acute effects of WBV alone or in combination with squatting plus external load (WBV+S) on serum GH levels and blood lactate concentrations in 7 severely obese women (age $22 \pm 5$ years; BMI $39.9 \pm 2.9 \mathrm{~kg} / \mathrm{m}^{2}$ ). Results: WBV and $\mathrm{WBV}+\mathrm{S}$ determined a significant GH increase (mean GH peaks $5.1 \pm 1.9 \mathrm{ng} / \mathrm{ml}, \mathrm{p}<0.001 \mathrm{vs}$. basal, and $6.5 \pm 3.7 \mathrm{ng} / \mathrm{ml}, \mathrm{p}<0.001$ vs. basal, respectively), GH peaks occurring immediately after both exercise sessions. No significant differences were observed between GH peaks and $\mathrm{GH}$ net incremental area under the curve (nAUC) after both conditions ( $p=0.39$ and $p=0.53$, respectively), the whole pattern of $\mathrm{GH}$ responsiveness being comparable among all the subjects. Lactate concentrations increased after both conditions (mean lactate peaks $2.0 \pm 0.5 \mathrm{mmol} / \mathrm{l}, \mathrm{p}<0.05 \mathrm{vs}$. basal, and $4.5 \pm 2.0 \mathrm{mmol} / \mathrm{l}, \mathrm{p}<0.001 \mathrm{vs}$. basal, respectively). The lactate response was significantly higher after WBV+S than after WBV $(p<0.05)$. Baseline
\end{abstract}


GH and GH peak values positively correlated to baseline lactate and lactate peak concentrations in both conditions $\left(R^{2}=0.64, p<0.001\right.$, and $R^{2}=0.52, p<0.05$, respectively). Conclusions: WBV alone stimulates $\mathrm{GH}$ release and lactate production in severely obese female subjects, with no additive effect when combined with squatting plus external load. Further additional studies are required to verify the chronic effects of WBV exercise on the GH/IGF-1 system, which could represent a potentially effective approach for weight management in obese subjects.

Copyright (c) 2012 S. Karger GmbH, Freiburg

\section{Introduction}

In the last years, whole body vibration (WBV) has been recognized as a useful alternative exercise modality to resistance exercise for its ability in enhancing force and powergenerating capacity in skeletal muscle [1,2], increasing bone mass [3, 4], and improving cardiovascular function $[5,6]$.

Even though the effects of vibrations on the endocrine system have been controversially discussed in the literature $[7,8]$, most of the studies so far conducted have reported an acute increase in circulating growth hormone (GH) levels in healthy subjects [9-11].

As observed with other GH-releasing stimuli (i.e. growth hormone-releasing hormone (GHRH), hexarelin, aerobic exercise, etc.) [12-16], administration of two consecutive bouts of WBV interspread by a 2-hour interval is associated with a blunting of GH responsiveness [17], thus suggesting the existence of a common mechanism underlying stimulation of somatotropic axis. By contrast, we have recently demonstrated that non-voluntary physical exercise (in the form of electrical stimulation of lower limb muscles) was capable to maintain GH responsiveness also after a 2nd bout repeated after a 2-hour interval [18], thus indicating a different mechanism operating specifically in this experimental setting.

It is well established that in obese subjects both pulsatile spontaneous GH secretion [19-22] and GH responsiveness to different GH-releasing stimuli are markedly decreased [23-29]. Furthermore, obesity is also reported to attenuate the GH releasing effects of aerobic exercise [30]. This hyporesponsiveness has been clearly shown to be a consequence of obesity (rather than the cause), since normal GH responses to exercise have been shown to reappear following a consistent period of marked weight loss [31,32].

To our knowledge, there are no studies on the acute GH-releasing effect of WBV in obese subjects who could benefit from the well-known lipolytic and anabolic effects of an endogenously stimulated GH release [33, 34]. A recent study by Vissers et al. [35] has suggested that vibration superimposed to static or dynamic exercise requires larger oxygen uptake than conventional exercise modalities in obeseand overweight women. Furthermore, animal models have suggested the potential of vibration exercise to reduce adipogenesis [36], encouraging more studies to understand its potential applications in obese individuals.

Therefore, the aim of the present study was to evaluate the acute effects of WBV alone on GH responses in severely obese females. Since these patients are reported to be hyporesponsive to classical GH-releasing stimuli, the additive effect of a different physical exercise (squatting plus external load) on the WBV-induced GH release was also investigated. 
Giunta et al.: Growth Hormone-Releasing Effects of Whole Body Vibration Alone or

Combined with Squatting plus External Load in Severely Obese Female Subjects

\section{Material and Methods}

\section{Subjects}

Seven obese female adults (age range $18-30$ years, mean $( \pm$ SD) age $22 \pm 5$ years; height range $1.53-$ $1.69 \mathrm{~m}$, mean height $1.63 \pm 0.06 \mathrm{~m}$; weight range $86.7-116.0 \mathrm{~kg}$, mean weight $105.9 \pm 10.5 \mathrm{~kg}$; BMI range $35.5-44.0 \mathrm{~kg} / \mathrm{m}^{2}$, mean BMI $39.9 \pm 2.9 \mathrm{~kg} / \mathrm{m}^{2}$; fat free mass (FFM) range 45.7-58.6 kg; mean FFM $51.3 \pm$ $4.5 \mathrm{~kg}$; fat mass (FM) range 46.8-55.8\%, mean FM $51.4 \pm 4.0 \%$ ), recruited among the inhospital patients at the Italian Institute of Auxology (Piancavallo, Verbania, Italy), volunteered to participate in this study. All participants received a written informed consent, and the study protocol was approved by the Ethical Committee of the Italian Institute of Auxology.

None of the subjects had evidence of any chronic illness or musculoskeletal disorder, including endocrine, hepatic, renal, thyroid, hypothalamo-pituitary or cardiac dysfunction, or were taking medications known to interfere with GH secretion. Women were tested during the early follicular phase of the menstrual cycle.

Subjects were asked to be refrained from any strenuous exercise for at least $48 \mathrm{~h}$ before each test. The subjects were admitted to the laboratory $1 \mathrm{~h}$ before the start of the treatments after an overnight fast (10-14 h); all treatments started between 8.00 and 8.30 AM.

\section{Experimental Procedures}

The study has a randomized cross-over design consisting of two different treatments administered in separate days in random order and separated by at least 3 days.

In the WBV treatment (WBV), the subjects remained on a vibrating platform (Nevisys $\mathrm{H} 1^{\circledR}$; RME, Ferrara, Italy) in a static squat position for $72 \mathrm{~s}$. The stimulus was repeated at the same condition for 10 consecutive series with a 50 -second rest in between.

In the second group in which WBV was combined with squatting plus external load (WBV+S), the subjects performed 10 consecutive series (separated by 50 -second rest) of 12 dynamic squats on the vibrating platform. During this test, subjects carried also an additional external load (contained in a vest, range $18-23 \mathrm{~kg}$ ) corresponding to $40 \%$ of their FFM as assessed by bioelectric impedance analysis (Human-IM scan; DS Medigroup, Milan, Italy) performed early in the morning after an overnight fast.

The whole duration of WBV and WBV+S was 19 min and $30 \mathrm{~s}$.

The vertical sinusoidal vibrations produced by the platform were set at a frequency of $30 \mathrm{~Hz}$; the acceleration of the platform was $2.85 \mathrm{~g}$, as assessed with the standing subjects by means of a magnetic monoaxial accelerometer (Vibration Meter, Lutron VB-8200, Taipei, Taiwan).

\section{Blood Sampling and Measurements}

Blood samples ( $5 \mathrm{ml}$ at each time point) were drawn before the start (baseline) and immediately after the end of each treatment session (time $=0 \mathrm{~min}$ ). The other time points were $t=10 \mathrm{~min}, \mathrm{t}=30 \mathrm{~min}$ and $\mathrm{t}=$ $60 \mathrm{~min}$ after the end of the experimental session. While the baseline blood sample was obtained by syringe venipuncture, the remaining ones were drawn through an indwelling cannula inserted into an antecubital vein kept patent by flushing with sterile $0.9 \%$ sodium chloride solution. All blood samples were centrifuged for $6 \mathrm{~min}$ at 4,000 rpm; the sera were separated and immediately stored at $-20^{\circ} \mathrm{C}$ until assayed.

GH concentrations were determined by a commercially available immunometric kit (Immulite ${ }^{\circledR} 2000$, DPC, Los Angeles, CA, USA). All samples were run in the same assay to minimize inter-assay variability. Intra- and inter-assay coefficients of variation were 2.5 and $6 \%$, respectively.

A small blood sample $(5 \mu \mathrm{l})$ was obtained from the earlobe for the determination of lactate concentration (carried out by a portable analyzer, Lactate Pro ${ }^{\mathrm{TM}}$, Arkray, Japan) at baseline, immediately at the end of the test, and at 2-min intervals until the detection of the first lactate concentration lower than the peak value. Intra- and inter-assay coefficients of variation were 3 and 7\%, respectively.

\section{Statistical Analysis}

All parameters were expressed as mean \pm SD. In addition to peak GH values, integrated GH concentration (net incremental area under the curve (nAUC)), including all the time points (from baseline to $t=$ $60 \mathrm{~min}$ ), was calculated by using the trapezoidal method [37].

GH and blood lactate responses were evaluated by means of both t-test and ANOVA followed by the Bonferroni's test. Standardized mean difference was evaluated as Cohen's d effect size. Correlations between baseline and peak values of GH and lactate concentrations were calculated by the Pearson Product Moment test. The statistical significance was set at $\mathrm{p}<0.05$. 


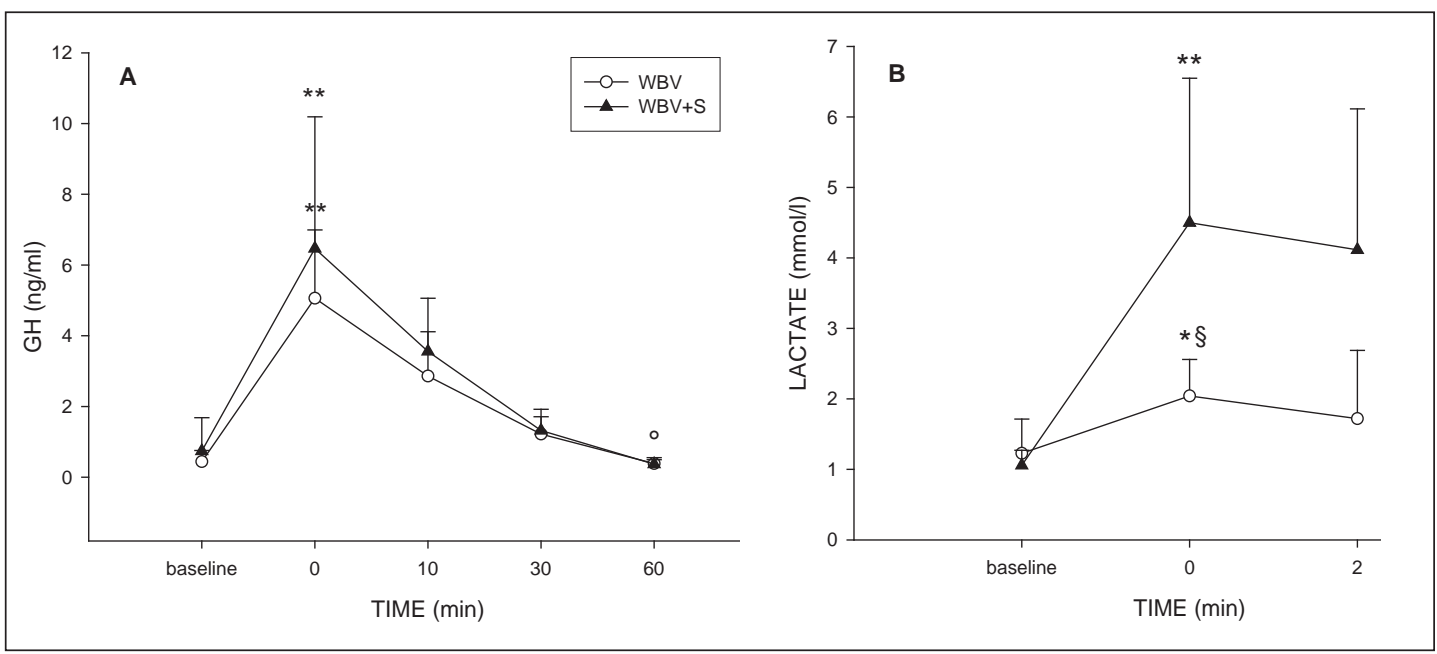

Fig. 1. A Mean ( \pm SD) GH responses to $W B V$ and $W B V+S$ in female obese subjects ( ${ }^{* *}$ basal vs. peaks, $p<$ 0.001 ; ${ }^{\circ}$ basal vs. $t=60 \mathrm{~min}, \mathrm{p}=\mathrm{NS}$ ). B Mean ( $\pm \mathrm{SD}$ ) lactate responses to $\mathrm{WBV}$ and $\mathrm{WBV}+\mathrm{S}$ in female obese subjects (**basal vs. peaks WBV, p $<0.001$; *basal vs. peaks WBV+S, p $<0.05$; ${ }^{\circledR}$ peak WBV vs. peak WBV+S, $\mathrm{p}<0.05)$.

\section{Results}

Baseline GH levels and lactate concentrations of patients were comparable at baseline in both treatments (mean GH: \pm SD: WBV $=0.4 \pm 0.3 \mathrm{ng} / \mathrm{ml} \mathrm{vs.} \mathrm{WBV+S} 0.7 \pm 0.9 \mathrm{ng} / \mathrm{ml}, \mathrm{p}=$ NS; mean lactate: WBV $1.2 \pm 0.5 \mathrm{mmol} / \mathrm{l} v \mathrm{vs}$ WBV+S $1.1 \pm 0.2 \mathrm{mmol} / \mathrm{l}, \mathrm{p}=\mathrm{NS}$ ).

WBV caused a significant increase in GH levels (mean GH peak: $5.1 \pm 1.9 \mathrm{ng} / \mathrm{ml} ; \mathrm{p}<$ 0.001 vs. basal). GH peaks occurred immediately at the end of the test, with a progressive reduction and a complete normalization at $t=60 \mathrm{~min}$, as shown in figure 1 (panel A). No statistically significant differences were found in mean GH concentrations between the baseline and the others time points $(t=10, t=30$ and $t=60 \mathrm{~min})$. Although the GH peaks range was wide $(2.7-8.2 \mathrm{ng} / \mathrm{ml})$, the whole pattern of $\mathrm{GH}$ responsiveness was comparable among all the subjects.

$\mathrm{WBV}+\mathrm{S}$ caused a significant increase in GH levels (mean GH peak $6.5 \pm 3.7 \mathrm{ng} / \mathrm{ml}, \mathrm{p}<$ 0.001 vs. basal). Similarly to the results of WBV, GH peaks occurred immediately at the end of the test, with a progressive reduction and a complete normalization at $t=60 \mathrm{~min}$, as reported in figure 1 (panel A). No statistically significant differences were found in mean $\mathrm{GH}$ concentrations between the baseline and the others time points $(\mathrm{t}=10, \mathrm{t}=30$ and $\mathrm{t}=60$ $\mathrm{min})$. Although the GH peaks range was wide $(2.7-11.9 \mathrm{ng} / \mathrm{ml})$, the whole pattern of $\mathrm{GH}$ responsiveness was comparable among all subjects.

No significant differences were observed between mean GH peaks and mean GH nAUCs after both treatments ( $\mathrm{p}=0.39$ and $\mathrm{p}=0.53$, respectively).

Both WBV and WBV+S caused a significant acute increase in lactate concentrations (mean lactate peaks $2.0 \pm 0.5 \mathrm{mmol} / \mathrm{l}, \mathrm{p}<0.05 v \mathrm{~s}$. basal, and $4.5 \pm 2.0 \mathrm{mmol} / \mathrm{l} ; \mathrm{p}<0.001$ $v s$. basal, respectively), the increase being significantly higher after $W B V+S(p<0.05)$ as reported in figure 1 (panel B). Lactate peaks occurred immediately at the end of the tests $(\mathrm{t}=0 \mathrm{~min})$.

Baseline GH and GH peak values positively correlated to baseline lactate and lactate peak concentrations both in $\mathrm{WBV}$ and $\mathrm{WBV}+\mathrm{S}\left(\mathrm{R}^{2}=0.64, \mathrm{p}<0.001\right.$, and $\mathrm{R}^{2}=0.52, \mathrm{p}<0.05$, respectively) as shown in figure 2 . 
Fig. 2. Correlations between baseline GH and GH peak values and baseline lactate and lactate peak concentrations in WBV and $\mathrm{WBV}+\mathrm{S}$.
Giunta et al.: Growth Hormone-Releasing Effects of Whole Body Vibration Alone or Combined with Squatting plus External Load in Severely Obese Female Subjects

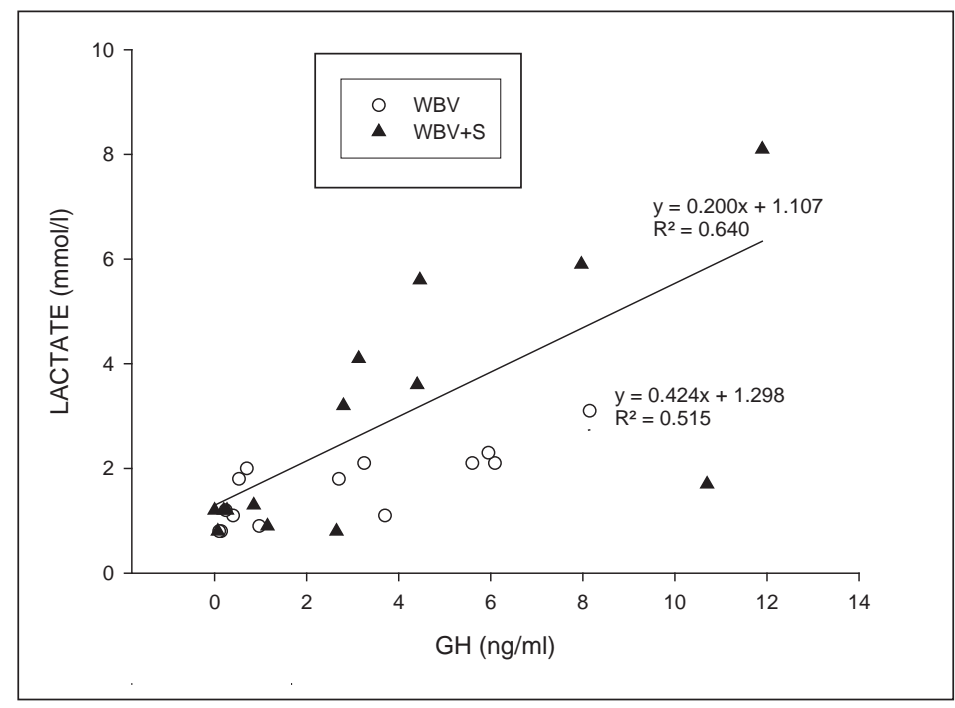

\section{Discussion}

It is well known that abdominal obesity is associated with decreased spontaneous 24-hour GH release [21,22] and reduced GH responsiveness to pharmacological stimuli [2329] and exercise [30]. The GH hyporesponsiveness of obese subjects restored after significant weight loss, thus suggesting that the obesity-related neuroendocrine alterations are secondary to the obese status and reversible [31,32].

Although the matter is controversial, this somatotropic hyporesponsiveness has been attributed to a central (hypothalamic) somatostatin hypertone or GHRH deficiency and/or peripheral factors, including the elevated plasma levels of nonesterified fatty acids (NEFAs) and free IGF-1, previously reported in obese subjects [25, 29, 34].

As shown by recent studies [9-11,17], WBV exercise is capable to increase GH secretion in healthy individuals, but, to the best of our knowledge, no studies have so far investigated the effects of acute WBV on GH levels in obese subjects.

Indeed, the main finding of this study was the significant WBV-induced increase of GH levels in severely obese females. Although the GH peak range was wide, the whole pattern of GH responsiveness was comparable among all the subjects. It is noteworthy that the GH-releasing effect of WBV in this group of obese subjects was quantitatively comparable to that previously observed by our group in healthy normal-weight subjects receiving the same WBV stimulus (GH peaks $4.3 \pm 3.5 \mathrm{ng} / \mathrm{ml}$ vs. $5.1 \pm 1.9 \mathrm{ng} / \mathrm{ml}$ ) [11,17].

Differently from other GH-releasing stimuli which are negatively influenced by the BMI degree, these findings seem to suggest the scarce influence of the body mass excess on the WBV-stimulated GH secretion.

Several mechanisms may be hypothesized to explain the occurrence of GH-releasing effect of WBV in severely obese subjects. In this respect, it is tempting to speculate on a direct afferent influence from WBV-stimulated muscles to the hypothalamic neurosecretory and autonomic centers, able to modulate GHRH and somatostatin tone without being influenced by the body mass (e.g., reducing the obesity-related somatostatin hypertone) [40].

In the present study, the addition of a physical exercise such as squatting plus external load did not further increase GH responses induced by WBV in obese female patients. 
The lack of any additive GH-releasing effect when WBV was associated to squatting plus external load seems a prerogative of obese subjects, since the combination of WBV and external load was reported to evoke a more pronounced GH peak in normal-weight subjects [10]. Similarly, the combination of maximal voluntary isometric contractions (MVC) with WBV was also associated with significant greater GH responses in healthy normal-weightsubjects [17], thus indicating that the GH-releasing effect of WBV is not maximal in this experimental setting. These findings in normal-weight subjects, combined with the results of the present study conducted in obese patients, would indicate that high-intensity exercise stimulates GH secretion through neuroendocrine mechanisms different from those of WBV.

The lack of additional effects exerted by squatting plus external load to WBV would support the use of WBV alone in the initial stages of a weight loss program, due to the limited stress upon joints and the GH-mediated stimulation of metabolism (such as lipolytic effect) without provoking an excessive fatigue.

In the present study, a significant increase of lactate concentrations was observed both after $\mathrm{WBV}$ alone and $\mathrm{WBV}+\mathrm{S}$, the increase being significantly higher after the latter. The positive correlation between serum GH levels and blood lactate concentrations would suggest a potential role of lactate in the mechanism underlying the WBV-induced GH secretion, as already hypothesized in our previous studies in healthy normal-weight subjects $[11,17]$. However, the finding of higher blood lactate levels after WBV+S, which stimulated the same GH release like WBV alone, forces us to keep some caution in considering lactate as an univocal determinant of WBV-induced GH secretion [41].

Some limitations of the present study need to be mentioned. First of all, only serum GH levels were evaluated, disregarding other hormones known to be acutely affected by WBV, such as cortisol. Secondly, the results were obtained in a relatively small number of obese patients, though the limited spread of data should be positively considered.

In conclusion, WBV alone stimulates GH release and lactate production in severely obese female subjects, with no additive effects when combined with squatting plus external load equal to $40 \%$ of the subject's fat free mass.

Further long-term studies are mandatory to determine the number of daily/weekly WBV sessions necessary to elicit positive effects on body composition and weight in order to better understand the potential use of WBV as an additional tool for the management of obese subjects.

\section{Acknowledgements}

The authors acknowledge Mrs. Franca Pera, headnurse, and the nursing staff at the Division of Metabolic Diseases, Istituto Auxologico Italiano, for their kind collaboration to the recruitment of the study group and Dr. Gabriella Tringali for her technical assistance during the experiments. The authors are indebted to all patients who participated enthusiastically to the present study. The study was partially supported by Progetti di Ricerca Corrente, Istituto Auxologico Italiano, Milan, Italy. The research was carried out as a collaborative project between members of the study group 'Ottimizzazione della performance motoria: ruolo dei fattori endocrini' of the Italian Society for Endocrinology, Rome, Italy.

\section{Disclosure Statement}

All authors disclose any sponsorship or funding arrangements relating to their research and any actual or potential conflicts of interest including any financial or personal relationship that could inappropriately influence their work. 
Giunta et al.: Growth Hormone-Releasing Effects of Whole Body Vibration Alone or

Combined with Squatting plus External Load in Severely Obese Female Subjects

\section{References}

- 1 Cardinale M, Lim J: Electromyography activity of vastus lateralis muscle during whole-body vibrations of different frequencies. J Strength Cond Res 2003;17:621-624.

- 2 Delecluse C, Roelants M, Verschueren S: Strength increase after whole-body vibration compared with resistance training. Med Sci Sports Exerc 2003;35:1033-1041.

3 Prisby RD, Lafage-Proust MH, Malaval L, Belli A, Vico L: Effects of whole body vibration on the skeleton and other organ systems in man and animal models: what we know and what we need to know. Ageing Res Rev 2008;7:319-329.

- 4 Totosy de Zepetnek JO, Giangregorio LM, Craven BC: Whole-body vibration as potential intervention for people with low bone mineral density and osteoporosis: a review. J Rehabil Res Dev 2009;46:529-542.

5 Lohman EB 3rd, Petrofsky JS, Maloney-Hinds C, Betts-Schwab H, Thorpe D: The effect of whole body vibration on lower extremity skin blood flow in normal subjects. Med Sci Monit 2007;13:CR71-CR76.

- 6 Bogaerts AC, Delecluse C, Claessens AL, Troosters T, Boonen S, Verschueren SM: Effects of whole body vibration training on cardiorespiratory fitness and muscle strength in older individuals (a 1-year randomised controlled trial). Age Ageing 2009;38:448-454.

7 Di Loreto C, Ranchelli A, Lucidi P, Murdolo G, Parlanti N, De Cicco A, Tsarpela O, Annino G, Bosco C, Santeusanio F, Bolli GB, De Feo P: Effects of whole-body vibration exercise on the endocrine system of healthy men. J Endocrinol Invest 2004;27:323-327.

8 Cardinale M, Soiza RL, Leiper JB, Gibson A, Primrose WR: Hormonal responses to a single session of whole body vibration exercise in older individuals. Br J Sports Med 2010;44:284-288.

- 9 Bosco C, Iacovelli M, Tsarpela O, Cardinale M, Bonifazi M, Tihanyi J, Viru M, De Lorenzo A, Viru A: Hormonal responses to whole-body vibration in men. Eur J Appl Physiol 2000;81:449-454.

-10 Kvorning T, Bagger M, Caserotti P, Madsen K: Effects of vibration and resistance training on neuromuscular and hormonal measures. Eur J Appl Physiol 2006;96:615-625.

-11 Sartorio A, Agosti F, De Col A, Marazzi N, Rastelli F, Chiavaroli S, Lafortuna CL, Cella SG, Rigamonti AE: Growth hormone and lactate responses induced by maximal isometric voluntary contractions and wholebody vibrations in healthy subjects. J Endocrinol Invest 2011;34:216-221.

12 Sartorio A, Spada A, Morabito F, Faglia G: Different GH responsiveness to repeated GHRH administration in normal children and adults. J Endocrinol Invest 1988;11:727-729.

-13 Ghigo E, Mazza E, Corrias A, Imperiale E, Goffi S, Arvat E, Bellone J, De Sanctis C, Müller EE, Camanni F: Effect of cholinergic enhancement by pyridostigmine on growth hormone secretion in obese adults and children. Metabolism 1989;38:631-633.

-14 Sartorio A, Spada A, Conti A, Grugni G, Morabito F, Faglia G: Galanin infusion partially restores the blunted growth hormone responses to repeated growth hormone releasing hormone stimuli in normal adults. J Endocrinol Invest 1993;16:95-98.

15 Sartorio A, Conti A, Ferrero S, Spada A, Faglia G: GH responsiveness to repeated GHRH or hexarelin administration in normal adults. J Endocrinol Invest 1995;18:718-722.

16 Sartorio A, Agosti F, Marinone PG, Proietti M, Lafortuna CL: Growth hormone responses to repeated bouts of aerobic exercise with different recovery intervals in cyclists. J Endocrinol Invest 2005;28:RC11-RC14.

$\checkmark 17$ Sartorio A, Lafortuna CL, Maffiuletti NA, Agosti F, Marazzi N, Rastelli F, Rigamonti AE, Muller EE: GH responses to two consecutive bouts of whole body vibration, maximal voluntary contractions or vibration alternated with maximal voluntary contractions administered at 2-h intervals in healthy adults. Growth Horm IGF Res 2010;20:416-421.

18 Sartorio A, Jubeau M, Agosti F, De Col A, Marazzi N, Lafortuna CL, Maffiuletti NA: GH responses to two consecutive bouts of neuromuscular electrical stimulation in healthy adults. Eur J Endocrinol 2008;158: 311-316.

19 Veldhuis JD, Iranmanesh A, Ho KK, Waters MJ, Johnson ML, Lizarralde G: Dual defects in pulsatile growth hormone secretion and clearance subserve the hyposomatotropism of obesity in man. J Clin Endocrinol Metab 1991;72:51-59.

-20 Veldhuis JD, Liem AY, South S, Weltman A, Weltman J, Clemmons DA, Abbott R, Mulligan T, Johnson ML, Pincus S: Differential impact of age, sex steroid hormones, and obesity on basal versus pulsatile growth hormone secretion in men as assessed in an ultrasensitive chemiluminescence assay. J Clin Endocrinol Metab 1995;80:3209-3222.

21 Clasey JL, Weltman A, Weltman JY, Chapman IM, Pezzoli SS, Teates CD, Bouchard C, Thorner MO, Hartman ML: Abdominal visceral fat (AVF) is related to 24-h growth hormone (GH) release in both young and older men and women. 79th Annual Meeting of The Endocrine Society 1997;107(Abstract OR 29-3).

22 Vahl N, Jørgensen JO, Skjaerbaek C, Veld huis JD, Orskov H, Christiansen JS: Abdominal adiposity rather than age and sex predicts mass and regularity of GH secretion in healthy adults. Am J Physiol 1997;272:E1108E1116.

23 Williams T, Berelowitz M, Joffe SN, Thorner MO, Rivier J, Vale W, Frohman LA: Impaired growth hormone responses to growth hormone-releasing factor in obesity. A pituitary defect reversed with weight reduction. N Engl J Med 1984;311:1403-1407. 
Giunta et al.: Growth Hormone-Releasing Effects of Whole Body Vibration Alone or

Combined with Squatting plus External Load in Severely Obese Female Subjects

24 Kelijman M, Frohman LA: Enhanced growth hormone (GH) responsiveness to GH-releasing hormone after dietary manipulation in obese and nonobese subjects. J Clin Endocrinol Metab 1988;66:489-494.

25 Cordido F, Dieguez C, Casanueva FF: Effect of central cholinergic neurotransmission enhancement by pyridostigmine on the growth hormone secretion elicited by clonidine, arginine, or hypoglycemia in normal and obese subjects. J Clin Endocrinol Metab 1990;70:1361-1370.

-26 Tanaka K, Inoue S, Numata K, Okazaki H, Nakamura S, Takamura Y: Very-low-calorie diet-induced weight reduction reverses impaired grow th hormone secretion response to growth hormone-releasing hormone, arginine, and L-dopa in obesity. Metabolism 1990;39:892-896.

-27 Cordido F, Peñalva A, Dieguez C, Casanueva FF: Massive growth hormone (GH) discharge in obese subjects after the combined administration of GH-releasing hormone and GHRP-6:evidence for a marked somatotroph secretory capability in obesity. J Clin Endocrinol Metab 1993;76:819-823.

-28 Vahl N, Jørgensen JO, Jurik AG, Christiansen JS: Abdominal adiposity and physical fitness are major determinants of the age associated decline in stimulated GH secretion in healthy adults. J Clin Endocrinol Metab 1996;81:2209-2215.

29 Maccario M, Valetto MR, Savio P, Aimaretti G, Baffoni C, Procopio M, Grottoli S, Oleandri SE, Arvat E, Ghigo E: Maximal secretory capacity of somatotrope cells in obesity: comparison with GH deficiency. Int J Obes Relat Metab Disord 1997;21:27-32.

-30 Kanaley JA, Weatherup-Dentes MM, Jaynes EB, Hartman ML: Obesity attenuates the growth hormone response to exercise. J Clin Endocrinol Metab 1999;84:3156-3161.

-31 Crockford PM, Salmon PA: Hormones and obesity: changes in insulin and growth hormone secretion following surgically induced weight loss. Can Med Assoc J 1970;103:147-150.

-32 Rasmussen MH, Hvidberg A, Juul A, Main KM, Gotfredsen A, Skakkebaek NE, Hilsted J, Skakkebae NE: Massive weight loss restores 24-hour growth hormone release profiles and serum insulin-like growth factor-I levels in obese subjects. J Clin Endocrinol Metab 1995;80:1407-1415.

-33 Slavin BG, Ong JM, Kern PA: Hormonal regulation of hormone-sensitive lipase activity and mRNA levels in isolated rat adipocytes. J Lipid Res 1994;35:1535-1541.

-34 Scacchi M, Pincelli AI, Cavagnini F: Growth hormone in obesity. Int J Obes Relat Metab Disord 1999;23: 260-271.

-35 Vissers D, Baeyens JP, Truijen S, Ides K, Vercruysse CC, Van Gaal L: The effect of whole body vibration shortterm exercises on respiratory gas exchange in overweight and obese women. Phys Sportsmed 2009;37: 88-94.

-36 Rubin CT, Capilla E, Luu YK, Busa B, Crawford H, Nolan DJ, Mittal V, Rosen CJ, Pessin JE, Judex S: Adipogenesis is inhibited by brief, daily exposure to high-frequency, extremely low-magnitude mechanical signals. Proc Natl Acad Sci U S A 2007;104:17879-17884.

-37 Sartorio A, De Nicolao G, Liberati D: An improved computational method to assess pituitary responsiveness to secretagogue stimuli. Eur J Endocrinol 2002;147:323-332.

-38 Prange Hansen A: Serum growth hormone response to exercise in non-obese and obese normal subjects. Scand J Clin Lab Invest 1973;31:175-178.

-39 Weltman A, Weltman JY, Veldhuis JD, Hartman ML: Body composition, physical exercise, growth hormone and obesity. Eat Weight Disord 2001;6:28-37.

40 Cardinale M, Leiper J, Erskine J, Milroy M, Bell S: The acute effects of different whole body vibration amplitudes on the endocrine system of young healthy men: a preliminary study. Clin Physiol Funct Imaging 2006; 26:380-384.

-41 Luger A, Watschinger B, Deuster P, Svoboda T, Clodi M, Chrousos GP: Plasma growth hormone and prolactin responses to graded levels of acute exercise and to a lactate infusion. Neuroendocrinology 1992;56:112117. 